\title{
Preparation, characterization and catalytic performance of single-atom catalysts
}

\author{
Liqiong Wang a, Liang Huang a,\#, Feng Liang b, Simin Liu b, Yuhua Wang c, Haijun Zhang a,* \\ a The State Key Laboratory of Refractories and Metallurgy, Wuhan University of Science and Technology, Wuhan 430081, Hubei, China \\ b School of Chemistry and Chemical Engineering, Wuhan University of Science and Technology, Wuhan 430081, Hubei, China \\ c Hubei Province Key Laboratory of Science in Metallurgical Process, Wuhan University of Science and Technology, Wuhan 430081, Hubei, China
}

\section{A R T I C L E I N F O}

\section{Article history:}

Received 29 October 2016

Accepted 19 December 2016

Published 5 September 2017

\section{Keywords:}

Single atom catalyst

Preparation method

Catalytic activity

Characterization

Electronic properties

\begin{abstract}
A B S T R A C T
Supported and colloidal single-atom catalysts (SACs), which possess excellent catalytic properties, are particularly important in both fundamental studies and practical applications. The progress made in the preparation methods, characterization, catalytic performances and mechanisms of SACs anchored to metal oxides, two-dimensional materials and the surface of metal nanoclusters (NCs) are reviewed. The different techniques for SAC fabrication, including conventional solution methods based on co-precipitation, incipient wetness co-impregnation, and the chemical vapor deposition method, as well as the newer atom layer deposition (ALD) and galvanic replacement methods, are summarized. The main results from experimental and theoretical studies of various catalytic reactions over SACs, including oxidation reactions, hydrogenation, water gas shift, photocatalytic $\mathrm{H}_{2}$ evolution and electrochemical reactions, are also discussed. Moreover, the electronic properties of the single atoms and their interactions with the supports are described to assist in understanding the origin of the high catalytic activity and selectivity of SACs. Finally, possible future research directions of SACs and their applications are proposed.
\end{abstract}

(C) 2017, Dalian Institute of Chemical Physics, Chinese Academy of Sciences. Published by Elsevier B.V. All rights reserved.

\section{Introduction}

Supported and colloidal metal catalysts play important roles in a large number of chemical reactions owing to their high catalytic activity and/or selectivity [1-6]. The size of the metal particle is a major factor determining their catalytic performance, and the specific activity of these catalysts increases with decreasing the metal particle size. For example, the catalytic activity for aerobic glucose oxidation of poly( $N$-vinyl-2-pyrrolidone) (PVP)-protected colloidal Au nanoclusters (NCs) increased with a decrease of their average diameter from ap- proximately 100 to $2.6 \mathrm{~nm}$ [7], and similar results were observed for colloidal $\mathrm{Au}_{80} \mathrm{Pt}_{20}$ bimetallic NCs [8] and $\mathrm{Au}_{70} \mathrm{Pt}_{20} \mathrm{Ag}_{10}$ trimetallic NCs [9]. Additionally, as has been well documented in the literature, sub-nanometer clusters exhibit better catalytic activity and selectivity than their nanometer counterparts [10-12]. Upon decreasing the size of metal nanostructures from the nanometer to the sub-nanometer scale, and ultimately to single atoms, the catalytic performance could be substantially changed as a result of the low-coordination environment, quantum size effect, and improved strong metal-support interaction [13].

\footnotetext{
* Corresponding author. Tel/Fax: +86-27-68862829; E-mail: zhanghaijun@wust.edu.cn

\# Corresponding author. Tel: +86-27-68862258; E-mail: huangliang1986@wust.edu.cn

This work was supported by the National Natural Science Foundation of China (51472184 and 51472185), the Science and Technology Support Program of Hubei Province (2013BHE003), and the Program for Innovative Teams of Outstanding Young and Middle-Aged Researchers in the Higher Education Institutions of Hubei Province (T201602).

DOI: 10.1016/S1872-2067(17)62770-0 | http://www.sciencedirect.com/science/journal/18722067 | Chin. J. Catal., Vol. 38, No. 9, September 2017
} 
Single-atom catalysts (SACs) containing isolated metal atoms mono-dispersed on supports that possess excellent catalytic properties have attracted a great deal of research interest because they are ideal catalysts for minimizing the use of expensive noble metals [14]. SACs can be successfully synthesized by various approaches and their use has proven to be superior for many conventional chemical reactions including oxidation reactions [15-20], hydrogenation [21-24], water-gas shift [25,26], and photocatalytic $\mathrm{H}_{2}$ evolution [27]. In addition, they have been found to be effective in several frontier areas, such as in sculpting graphene morphology [28], medical applications [29] and electrochemical reactions [30,31]. Recently, considerable efforts have been made worldwide in the preparation and catalytic performance evaluation of SACs. Great progress has been made and many promising results have been reported.

In this review, we provide an overview of the recent studies on the preparation, characterization, catalytic activity and mechanism of the following three representative types of SACs: SACs anchored to metal oxides (Fig. 1(a)), two-dimensional materials (Fig. 1(b)) and the surface of metal NCs (Fig. 1(c)). In the last section, we will briefly discuss the current development, expected improvements and future outlook in this research area.

\section{SACs anchored to metal oxides}

Noble metal catalysts downsized to clusters or single-metal atoms are structurally unstable owing to their natural tendency for high activity and a large specific surface area. Thus, supports, which can efficiently stabilize single atoms, are crucial for the performance of SACs. So far, various metal oxides have been attempted to anchor single atoms, such as $\mathrm{FeO}_{x}$ [20], $\mathrm{SiO}_{2}$ [23] and $\mathrm{TiO}_{2}$ [32]. Generally, SACs anchored to metal oxides usually exhibit several advantages, including easy fabrication by using feasible preparation methods, such as co-precipitation, photochemical strategy and co-impregnation, and are relatively cheaper than other supports, such as graphene and noble metal NCs.

Zhang's group were the first to propose the concept of SACs and synthesized a series of Pt- [20], Ir- [25] and Au- [33,34] based SACs. The SACs were anchored onto the metal oxides by carefully tuning the co-precipitation conditions in addition to controlling the concentration of the metal precursors. The anchored SACs exhibited excellent catalytic performance in CO oxidation, the preferential oxidation of $\mathrm{CO}$ in $\mathrm{H}_{2}$ and water-gas shift reactions, and the results indicated that the SACs were

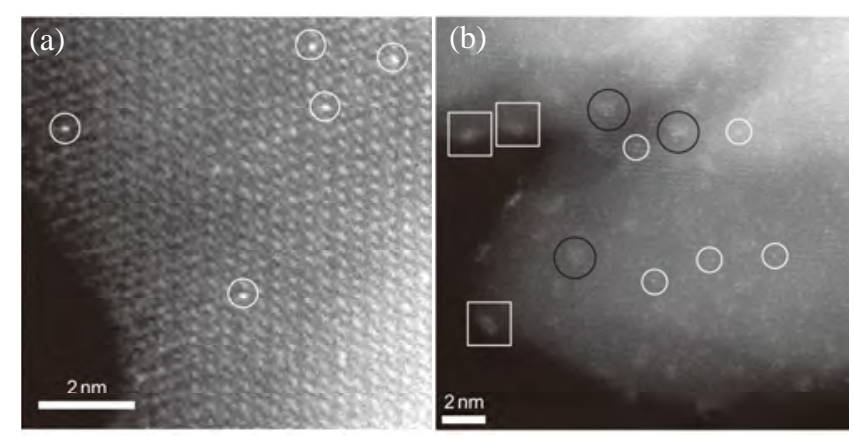

Fig. 2. HAADF-STEM images of $\mathrm{Pt} / \mathrm{FeO}_{x} \mathrm{SACs}$ sample (a) and nanocluster sample (b). Reprinted with permission from Ref. [20]. Copyright 2011 Nature Publishing Group.

more active, selective and stable than their conventional nanoparticle counterparts in all cases.

By using high-angle annular dark-field scanning transmission electron microscopy (HAADF-STEM) in combination with $\mathrm{X}$-ray absorption fine structure spectroscopy and density functional theory (DFT) calculations, Zhang's group [20] determined the exact structures of $\mathrm{Pt} / \mathrm{FeO}_{x}$ SACs. As shown in Fig. 2 (a), single atoms of Pt were uniformly dispersed on the $\mathrm{FeO}_{x}$ support and located exactly at the positions of the Fe atoms. When the Pt loading was higher, two-dimensional Pt rafts and three-dimensional Pt clusters appeared, in addition to the individual Pt atoms (Fig. 2(b)). The extended X-ray absorption fine structure (EXAFS) spectra revealed that the Pt-O bonding distance was close to that in $\mathrm{PtO}_{2}$, indicating the oxidation state of Pt and the strong metal-support interaction. The white line intensity in the X-ray absorption near-edge structure (XANES) spectra, which reflects the oxidation state of Pt in the SACs sample, was intermediate between the intensities of Pt foil and $\mathrm{PtO}_{2}$, while the other samples clearly showed lower white line intensities, further indicating that the Pt single atoms carried positive charges. To investigate the catalytic performance of the $\mathrm{Pt} / \mathrm{FeO}_{x} \mathrm{SACs}, \mathrm{CO}$ oxidation and the preferential oxidation of $\mathrm{CO}$ in $\mathrm{H}_{2}$ were chosen as the probe reactions. The results showed that $\mathrm{Pt} / \mathrm{FeO}_{x} \mathrm{SACs}_{\mathrm{s}}$ were the most active for both reactions among a number of supported Pt catalysts. Since the support itself was essentially inactive for the preferential oxidation of $\mathrm{CO}$ in the $\mathrm{H}_{2}$ reaction at $80^{\circ} \mathrm{C}$, the high activity of $\mathrm{Pt} / \mathrm{FeO}_{x} \mathrm{SACs}$ should originate from the intrinsic nature of single Pt atoms dispersed onto the $\mathrm{FeO}_{x}$ surfaces. DFT calculations were also conducted to elucidate the nature of the binding of Pt single atoms to the $\mathrm{FeO}_{x}$ support and the exceptionally high catalytic activity of single Pt atoms (Fig. 3). After pre-treatment by $\mathrm{H}_{2}$,

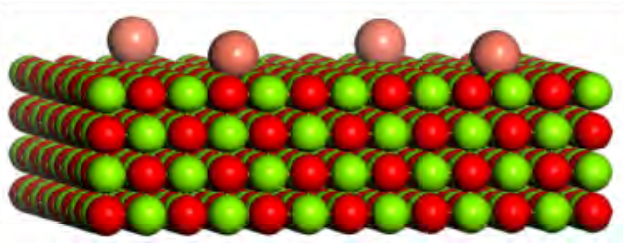

(a)

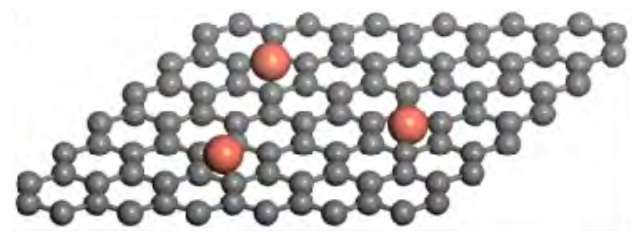

(b)

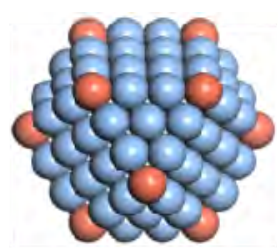

(c)

Fig. 1. Schematic diagrams illustrating SACs on different supports: single metal atoms anchored to (a) metal oxides, (b) two-dimensional materials, and (c) the surface of metal NCs. 


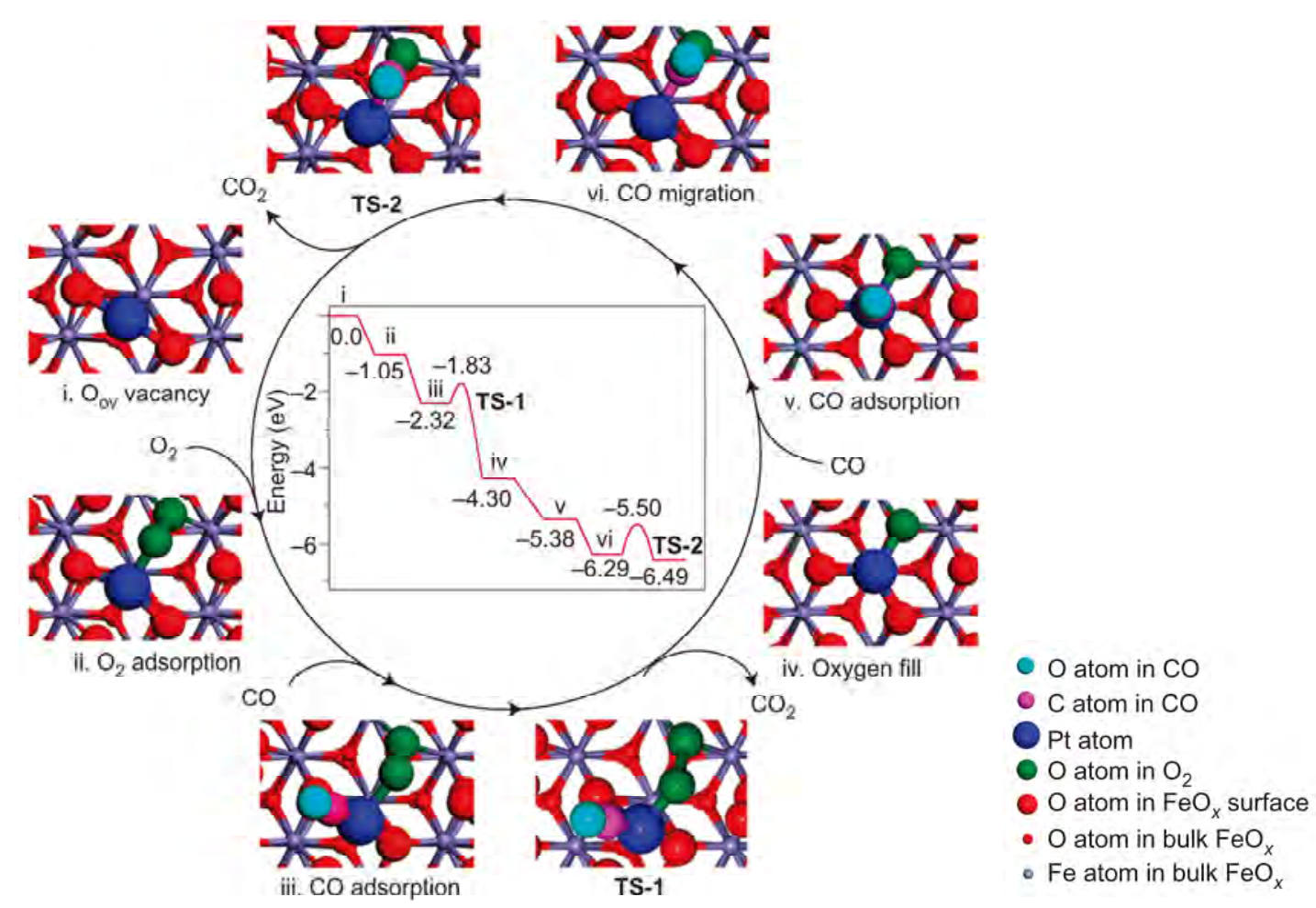

Fig. 3. The proposed reaction pathways for $\mathrm{CO}$ oxidation on the $\mathrm{Pt} / \mathrm{FeO}_{x}$ catalyst. The inset in the cycle shows the calculated energy profile, with the partially reduced sample as the reference for the energies (in eV). Reproduced with permission from Ref. [20]. Copyright 2011 Nature Publishing Group.

the stoichiometric haematite surfaces near the Pt atoms were partially reduced to form an $\mathrm{O}_{\text {vac }}$ (step i) that can adsorb the $\mathrm{O}_{2}$ reactants (step ii). Subsequently, the CO was adsorbed on the single $\mathrm{Pt}$ atoms (step iii) to react with the adsorbed $\mathrm{O}_{2}$ reactant. Through an activation barrier of $0.49 \mathrm{eV}$ (TS-1), the first $\mathrm{CO}_{2}$ molecule was released and the surface oxygen vacancy was healed by the remaining $\mathrm{O}_{a d}$ atom of the $\mathrm{O}_{2}$ reactant (step iv). When the second CO molecule was adsorbed at the Pt atom (step v), it migrated to a neighboring oxygen atom (step vi) to form a transition state with a barrier of $0.79 \mathrm{eV}$ (TS-2), which led to the oxidation of a new $\mathrm{CO}$ molecule. By releasing the second $\mathrm{CO}_{2}$ molecule, the Pt-embedded stoichiometric surface was reduced again to form a new $\mathrm{O}_{\mathrm{vac}}$ (step i). After one catalytic cycle, the catalyst was recovered and released two $\mathrm{CO}_{2}$ molecules. This showed that all the elementary steps in the catalytic cycle were exothermic and the barriers were sufficiently low for CO oxidation at low temperatures. DFT calculations also showed that the high catalytic activity correlated with the partially vacant $5 d$ orbitals of the positively charged, high-valent Pt atoms, which contributed to the reduction in the $\mathrm{CO}$ adsorption energy and the activation barriers for CO oxidation.

Recently, a series of $\mathrm{Ir} / \mathrm{FeO}_{x}$ catalysts with different Ir loadings were synthesized through a co-precipitation method by Zhang and his colleagues [25], and HAADF-STEM revealed that the individual Ir atoms occupied exactly the positions of the Fe atoms. Extensive studies revealed that the single atoms served as the most important active sites because they accounted for $\sim 70 \%$ of the total activity of catalysts toward the water-gas shift reaction. The activity of $\mathrm{Ir} / \mathrm{FeO}_{x}$ SACs were one order of magnitude higher than their cluster or nanoparticle counterparts [35] and were even higher than those of the most active $\mathrm{Au}$ - or Pt-based catalysts. $\mathrm{H}_{2}$ temperature-programmed reduction results strongly suggested that the Ir single atoms greatly promoted the reduction of $\mathrm{FeO}_{x}$, resulting in large amounts of oxygen vacancies, which was likely to be the cause for the high activity for $\mathrm{H}_{2} \mathrm{O}$ dissociation to produce $\mathrm{H}_{2}$ and reactive oxygen species. The synergy between Ir single atoms and $\mathrm{FeO}_{x}$ led to an excellent performance of $\mathrm{Ir} / \mathrm{FeO}_{x} \mathrm{SACs}$. These findings could have broad implications on designing supported metal catalysts with better performance and lower cost.

Recently, Xing et al. [32] successfully synthesized $\mathrm{TiO}_{2}$ photocatalysts loaded with isolated Pt atoms by using a co-precipitation method. The HAADF-STEM image clearly illustrated that isolated Pt atoms occupied exactly the sites of the Ti atoms, and EXAFS analysis further demonstrated that only individual $\mathrm{Pt}$ atoms were dispersed in $\mathrm{Pt} / \mathrm{TiO}_{2}$ SACs with no Pt-Pt bonding and that Pt atoms exhibited an oxidation state. The as-prepared isolated metal atom based photocatalysts showed excellent stability for $\mathrm{H}_{2}$ evolution and led to a 6-13 fold increase in photocatalytic activity compared with the metal nanoparticles or clusters loaded on $\mathrm{TiO}_{2}$.

Zhang and co-workers [33] also prepared $\mathrm{Co}_{3} \mathrm{O}_{4}$-supported $\mathrm{Au}$ SACs with very low $\mathrm{Au}(0.05$ wt $\%)$ loading, and the as-prepared catalysts showed a high activity for CO oxidation and exhibited complete conversion of $\mathrm{CO}$ at room temperature. The high activity of the catalysts originated from the isolated $\mathrm{Au}$ atoms distributed over the $\mathrm{Co}_{3} \mathrm{O}_{4}$ nanocrystallites. The cat- 
alyst deactivation observed during the $\mathrm{CO}$ oxidation arose from the accumulation of $\mathrm{CO}_{2}$ rather than sintering among the single $\mathrm{Au}$ atoms. The low loading of $\mathrm{Au}$ coupled to a high activity is critical to reduce the use of noble metals and to make these catalysts more practical and attractive.

Apart from the co-precipitation method, the incipient wetness co-impregnation method was used for the synthesis of $\mathrm{Pd}$ single-atom alloys with $\mathrm{Au}, \mathrm{Ag}$ and $\mathrm{Cu}$ supported on silica gel by Zhang' group $[23,36]$. The Ag-alloyed Pd SACs, possessing only ppm levels of Pd, were prepared by the method and applied to the selective hydrogenation of acetylene in an ethylene-rich stream under industrial conditions [23]. Silica gel was impregnated with a mixture of $\mathrm{Pd}(\mathrm{NO})_{3}$ and $\mathrm{AgNO}_{3}$ solutions to achieve a nominal $\mathrm{Ag}$ loading of $5 \mathrm{wt} \%$ and different $\mathrm{Pd} / \mathrm{Ag}$ atomic ratios. High-temperature pre-reduction promoted the sintering of the bimetallic NCs, accompanied by restructuring of AgPd NCs and charge transfer from Ag to Pd, which were evidenced by in-situ FTIR and in-situ XPS as a function of increasing reduction temperature. Microcalorimetry and XANES measurements confirmed both geometric and electronic synergetic effects between the alloyed Pd and Ag. High acetylene conversion and simultaneous selectivity to ethylene were attained over a wide temperature window, surpassing an analogous Au-alloyed Pd single-atom system. In-depth characterization and theoretical studies revealed that the isolation of $\mathrm{Pd}$ atoms by another inert metal, together with the appropriate spatial arrangement of $\mathrm{Pd}$ sites in $\mathrm{Pd}$-alloy ensembles, give rise to the moderate $\sigma$-bonding mode for acetylene with two neighboring Pd sites, while the weak $\pi$-bonding pattern of ethylene gives rise to adsorption on the single Pd site. As a result, the chemisorption toward acetylene is facilitated and the desorption of ethylene from the catalyst surface is promoted, which led to the kinetically favorable selective hydrogenation of acetylene to ethylene, as shown in Fig. 4. By using the same method, silica gel supported Cu-alloyed Pd SACs were also prepared, over which $85 \%$ ethylene selectivity could be achieved with total acetylene elimination. The isolation of $\mathrm{Pd}$ by $\mathrm{Cu}$ and the electron transfer from $\mathrm{Cu}$ to $\mathrm{Pd}$ not only promoted the dissociation of $\mathrm{H}_{2}$, but also led to a weak adsorption for $\mathrm{C}_{2} \mathrm{H}_{4}$, resulting in a high selectivity to ethylene at high acetylene conversion. As $\mathrm{Cu}$ is a low-cost metal, Cu-alloyed Pd SACs

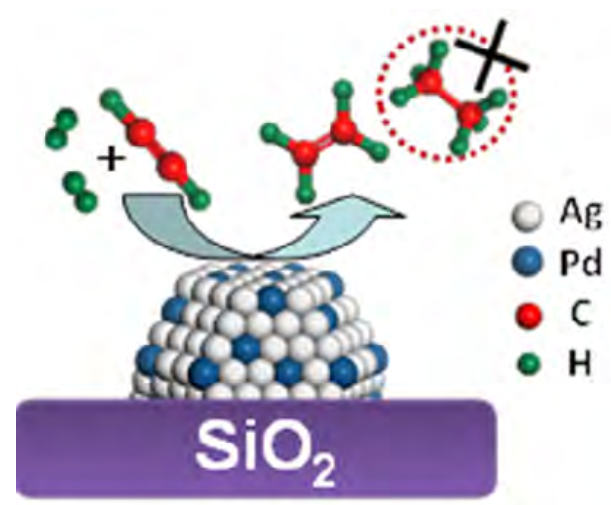

Fig. 4. Illustration of $\mathrm{AgPd}_{x} / \mathrm{SiO}_{2} \mathrm{SACs}$ used for selective hydrogenation of acetylene to ethylene. Reproduced with permission from Ref. [23]. Copyright 2015 American Chemical Society. would reduce the use of noble metals and possess a practical potential with high atom efficiency and low cost in industry. These as-prepared SACs can bridge the gap between homogeneous and heterogeneous catalysts in organic transformations and may provide a new vision to develop other efficient single-atom catalysts for the green synthesis of fine chemicals. Moreover, these achievements will inspire the exploration of other alloyed SACs which are efficient for selective hydrogenation reactions.

More recently, $\mathrm{Pt} / \theta-\mathrm{Al}_{2} \mathrm{O}_{3}$ SACs were synthesized using the incipient wetness co-impregnation method by Narula [37], and the results showed that: (1) unlike $\mathrm{Pt} / \mathrm{FeO}_{x} \mathrm{SAC}$, the platinum single atoms of $\mathrm{Pt} / \theta-\mathrm{Al}_{2} \mathrm{O}_{3} \mathrm{SACs}$ did not appear to be embedded in alumina, but were able to move on the surface; (2) $\mathrm{Pt} / \theta-\mathrm{Al}_{2} \mathrm{O}_{3} \mathrm{SACs}$ exhibited a catalytic activity 6-18 times that of a sub-nanometer Pt cluster anchored onto $\theta-\mathrm{Al}_{2} \mathrm{O}_{3}$ towards the reaction of CO oxidation; (3) DFT calculations suggested that the single Pt atoms were covered with intermediates $\left(\mathrm{CO}_{3}\right)$, which was evidenced by an in-situ diffuse reflectance infrared study of CO adsorption over this SAC. These results clearly indicated that supported Pt single atoms were catalytically active and that the catalytic activity can occur without involving the substrate.

Resin-supported Au-alloyed Pd SACs [36] were prepared with an ion exchange- $\mathrm{NaBH}_{4}$ reduction method and identified by a series of state-of-the-art characterizations. XRD indicated the formation of $\mathrm{Au} / \mathrm{Pd}$ alloys. The EXAFS and DRIFTS results demonstrated that with an increase of the $\mathrm{Au} / \mathrm{Pd}$ molar ratio, the continuous Pd ensembles on the surface were gradually separated and eventually isolated by Au atoms, confirming that Au-alloyed Pd SACs were formed. The catalysts exhibited excellent performance for the Ullmann reaction of aryl chlorides, and the turnover number increased exponentially with a decrease of the amount of Pd in the catalysts. On the basis of these characterization and catalytic results, the Au-alloyed Pd single-atom was proposed as the active site for the reaction. The catalyst exhibited excellent catalytic performance for a broad range of substrates and could be reused for at least 8 cycles with no change in yield.

The chemical adsorption method was also chosen to prepare SACs. Gu et al. [38] reported the preparation and catalytic activities for the methanol steam reforming of single Pt and $\mathrm{Au}$ atom catalysts stabilized on $\mathrm{ZnO}$ nanowires. DFT calculations revealed that the catalysis of the single precious metal atoms together with coordinated lattice oxygen stemmed from their stronger binding toward the intermediates, which can lower the reaction barriers, change the reaction pathway, and greatly enhance the activity. It was found the turnover frequency of single Pt sites embedded onto ZnO (1010) surfaces was 1000 times higher than that of the pristine $\mathrm{ZnO}$. These results provided valuable insights for the catalysis of single precious metal atoms dispersed on the oxide surfaces.

To study the nature of the electronic metal-support interaction independent of the intrinsic metal effects, a stable $\mathrm{MnO}_{2}$ supported single-atom silver catalyst with a controllable electronic state was obtained using the anti-Ostwald ripening method (AOR method) [39]. Briefly, $\mathrm{Ag} / \mathrm{MnO}_{2}$ was firstly pre- 
pared by using the redox reactions, and then $\mathrm{Ag} / \mathrm{MnO}_{2}$ was dried at $80{ }^{\circ} \mathrm{C}$ and calcined at $500{ }^{\circ} \mathrm{C}$ in air to obtain the $\mathrm{Ag}_{\mathrm{AOR}}-\mathrm{MnO}_{2}$ SAC sample. Compared with $\mathrm{Ag}_{\mathrm{IMP}}-\mathrm{MnO}_{2}$ SACs prepared by conventional wet impregnation, $\mathrm{Ag}_{\mathrm{AOR}}-\mathrm{MnO}_{2} \mathrm{SACs}$ possessed stronger electronic metal-support interactions. Therefore, the electronic metal-support interactions of single-atom silver catalysts can be controlled by the different preparation methods. The higher depletion of the $4 d$ electronic state of the silver atoms caused stronger electronic metal-support interactions, which led to easier reducibility and higher catalytic activity in the low temperature oxidation of formaldehyde. These results could improve our understanding of the nature of electronic metal-support interactions and lead to structure-activity correlations.

Zheng's group [40] reported a room-temperature photochemical strategy to fabricate a highly stable and atomically dispersed palladium-titanium oxide catalyst $\left(\mathrm{Pd} / \mathrm{TiO}_{2}\right)$ on ethylene glycolate (EG)-stabilized ultra-thin $\mathrm{TiO}_{2}$ nanosheets (with Pd loading up to $1.5 \%$ ). The as-prepared $\mathrm{Pd} / \mathrm{TiO}_{2}$ catalyst exhibited high catalytic activity for the hydrogenation of $\mathrm{C}=\mathrm{C}$ bonds, 9 times greater than that of surface Pd atoms on commercial $\mathrm{Pd} / \mathrm{C}$ catalysts. The catalyst was highly stable and durable as no decay in the activity was observed after 20 cycles. More importantly, the $\mathrm{Pd} / \mathrm{TiO}_{2}$ SACs could activate $\mathrm{H}_{2}$ in a heterolytic pathway, leading to a catalytic enhancement in the hydrogenation of aldehydes by a factor of more than 55 .

During the past decade, researchers have successfully synthesized SACs by using simple and feasible methods. Several strategies for atomically dispersing metal atoms have emerged, including lowering the loading amount of metal components, applying various supports, and introducing vacancies and defects on/in supports to tune the metal-support interactions. In summary, it can be concluded that: (1) SACs supported on metal oxides offer distinguished active sites and can undergo different catalytic pathways to conventional metal catalysts; (2) the low metallic loading ensures the metal centers behave as individual sites and results in high catalytic activities and selectivities for the SACs under catalytic conditions. Nonetheless, the low loading reduces the production efficiency of SACs and prevents their large-scale production; (3) experimental and theoretical studies show that the high catalytic activity of SACs correlates with the partially vacant orbitals of the positively charged, high-vacancy metal atoms owing to the strong electronic metal-support interactions. The synergistic effect of SACs makes positively charged metal atoms act as active sites to activate reactants and lower reaction barriers. These findings may provide us with a better understanding of the nature of electronic metal-support interactions and the structure-activity correlations of SACs.

\section{SACs anchored to two-dimensional materials}

Graphene and other two-dimensional atomic crystals are of considerable interest in catalysis because of their unique structural and electronic properties. Although many layered materials have long been used as catalysts in their three-dimensional forms, the considerable changes in the elec- tronic structure of 2D materials, as well as the possibility of chemical and structural modifications, has provided new opportunities to use 2D materials in many different chemical reactions [41,42]. 2D materials can also act as supports for SACs owing to their plentiful anchoring sites which can prevent agglomeration of single atoms. For instance, graphene $[29,43-45], \mathrm{C}_{3} \mathrm{~N}_{4}[22,27,46]$, hexagonal boron nitride $[47,48]$ and various other $2 \mathrm{D}$ materials $[49,50]$ have been used as supports to disperse single noble metal atoms.

Single-atom Pt/graphene catalyst has been synthesized by simply adjusting the atom layer deposition (ALD) cycle numbers and carefully controlling the nucleation sites on the supports [44]. The Pt/graphene SACs showed a much higher activity for methanol oxidation and superior CO tolerance compared with a conventional Pt/C catalyst, and the excellent electrochemical performance can be attributed to the more unsaturated $5 \mathrm{~d}$ orbital of the single Pt atoms. This work provided a promising approach for the design of next-generation highly active catalysts. The single-atom Pd/graphene catalyst [45], fabricated by the ALD technique, was evaluated in the selective hydrogenation of 1,3-butadiene. It showed a butene selectivity of approximately $100 \%$ and a superior catalytic performance at a mild reaction condition. In the presence of excessive propene, the propene stream was largely preserved by sufficiently suppressing its conversion to only $0.1 \%$. Moreover, the Pd/graphene SACs showed excellent durability against deactivation through either metal atom aggregation or carbonaceous deposits during a total reaction time of $100 \mathrm{~h}$. Both the mono- $\pi$-adsorption mode of 1,3 -butadiene and the enhanced steric effect induced by 1,3-butadiene adsorption on isolated Pd atoms were responsible for the vast improvement in butene selectivity. First-principles calculations, performed by Zhou et al. [51], demonstrated that the Fe atom could be efficiently constrained at a vacancy site of graphene and the Fe-embedded graphene could enhance the catalytic activity for CO oxidation. This indicated that the dispersive ability and catalytic activity of SACs was significantly determined by the vacancies on graphene.

To be able to disperse single metal atoms onto graphene, the bottleneck is the control of the carrier type and density in the progress to functionalize graphene. Wang et al. [28] demonstrated an efficient two-step process to dope graphene. They initially created vacancies by high-energy atom/ion bombardment and then anchored them to the desired dopants. The defect generation was realized in a pulsed laser deposition chamber with a background pressure of $10^{-8}$ Torr, and most dopants were deposited by a conventional sputtering tool with an Ar pressure of 50 mTorr and plasma power of $10 \mathrm{~W}$. Different elements, such as Pt, Co and In, were successfully doped in the single-atom form by this method. It was observed that monovacancies or bivacancies can be selectively created if the kinetic energy of the incoming atoms was confined within a certain energy range and the physisorption was restricted to the low energy end. The controllable vacancy generation by an atom/ion beam with narrow energy distribution and manipulable dosage was important for this technique.

MXenes are also promising candidate substrates for an- 
choring metal atoms [52,53], as they not only prevent single metal atoms from agglomeration but also provide a large specific surface area for fixing metal atoms as activation sites. 2D $\mathrm{Ti}_{2} \mathrm{CO}_{2}$ was proposed as a support for SACs by Zhou's group [49], and the reaction mechanism of $\mathrm{CO}$ oxidation catalyzed by the single atom $\mathrm{Ti} / \mathrm{Ti}_{2} \mathrm{CO}_{2}$ was investigated by using first-principles calculations. The calculation results indicated that the $\mathrm{Ti}_{2} \mathrm{CO}_{2}$ substrate could prevent Ti atoms from agglomeration owing to the high diffusion barriers. Additionally, the strong interaction between $\mathrm{O}_{2}$ and Ti-anchored $\mathrm{Ti}_{2} \mathrm{CO}_{2}$ SACs originated from the significant charge transfer from the catalysts to the anti-bonding $2 \pi$ orbital of $\mathrm{O}_{2}$ and the strong hybridization between the $d$-orbitals of Ti atoms and the $p$-orbitals of $\mathrm{O}_{2}$, which made $\mathrm{O}_{2}$ active on the catalysts to facilitate $\mathrm{CO}$ oxidation. Furthermore, the Eley-Rideal mechanism with a two-step route could be more preferential for the catalytic reaction under the experimental conditions, and the energy barriers were even comparable with those in the case of noble metal catalysts. The experimental achievement of $\mathrm{Ti} / \mathrm{Ti}_{2} \mathrm{CO}_{2}$ SACs with high activity for $\mathrm{CO}$ oxidation could be helpful to design more nonprecious-metal nanocatalysts for low-temperature $\mathrm{CO}$ oxidation and other reactions.

g- $\mathrm{C}_{3} \mathrm{~N}_{4}$ has attracted much attention because of its high stability, nontoxicity, and visible-light response [54]. It has also been used as a 2D support to anchor single metal atoms. Li et al. [27] reported an isolated single Pt atom catalyst anchored on $2 \mathrm{D}$ g- $\mathrm{C}_{3} \mathrm{~N}_{4}$ with high dispersivity and stability. The highly stable single-atom co-catalyst was prepared by a simple liquid-phase reaction using g- $\mathrm{C}_{3} \mathrm{~N}_{4}$ and $\mathrm{H}_{2} \mathrm{PtCl}_{6}$ followed by annealing at a low temperature. The reaction of the tri-s-triazine units in $\mathrm{C}_{3} \mathrm{~N}_{4}$ and $\mathrm{H}_{2} \mathrm{PtCl}_{6}$ generated rich $\mathrm{Pt}-\mathrm{N} / \mathrm{C}$ bonds, which endowed a relatively low-temperature synthesis of a single-atom $\mathrm{Pt}_{-} \mathrm{C}_{3} \mathrm{~N}_{4}$ system with high stability. The as-prepared Pt- $\mathrm{C}_{3} \mathrm{~N}_{4}$ SACs enhanced the photocatalytic $\mathrm{H}_{2}$ evolution activity and achieved a maximum use of the Pt atoms. EXAFS spectroscopy clearly confirmed that Pt atoms were dispersed on the g- $\mathrm{C}_{3} \mathrm{~N}_{4}$ network. It also revealed that the Pt-atom, which induced an intrinsic change of the surface trap states of $\mathrm{g}-\mathrm{C}_{3} \mathrm{~N}_{4}$, was the primary factor behind the improved photocatalytic performance. More recently, Gao et al. [55] investigated the catalytic photoactivity for $\mathrm{CO}_{2}$ hydrogenation of Pd and Pt single metal atoms supported on g- $\mathrm{C}_{3} \mathrm{~N}_{4}$, using DFT calculations. Their calculations showed that the six-fold cavity of g- $\mathrm{C}_{3} \mathrm{~N}_{4}$ was the most stable site for the deposition of Pd and Pt atoms. During the reaction, the noble atoms functioned as the active sites while the $\mathrm{g}-\mathrm{C}_{3} \mathrm{~N}_{4}$ was the the hydrogen source from the hydrogen evolution reaction (as shown in Fig. 5). The calculations on reaction barriers demonstrated that the preferred product of $\mathrm{CO}_{2}$ reduction on the $\mathrm{Pd} / \mathrm{g}-\mathrm{C}_{3} \mathrm{~N}_{4}$ catalyst was $\mathrm{HCOOH}$, while the $\mathrm{Pt} / \mathrm{g}-\mathrm{C}_{3} \mathrm{~N}_{4}$ catalyst was able to preferentially reduce $\mathrm{CO}_{2}$ to $\mathrm{CH}_{4}$. These single metal atoms supported on g- $\mathrm{C}_{3} \mathrm{~N}_{4}$ not only enhanced the visible-light absorption, but also made them perfect catalysts for visible-light reduction of $\mathrm{CO}_{2}$. This work provided a new approach for renewable energy supply by converting $\mathrm{CO}_{2}$ into fuel using solar energy.

Hexagonal boron nitride was also used as a support for the preparation of SACs owing to its high thermal stability and

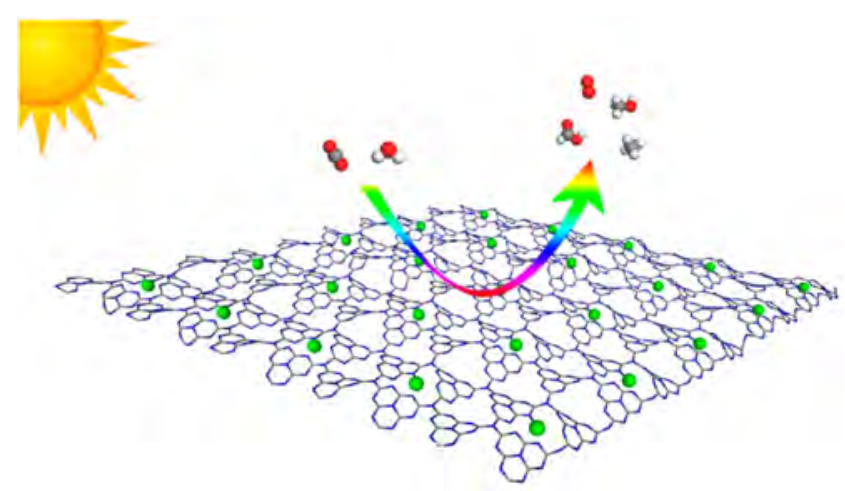

Fig. 5. Illustration of $\mathrm{CO}_{2}$ reduction on $\mathrm{Pd} / \mathrm{Pt}-\mathrm{C}_{3} \mathrm{~N}_{4} \mathrm{SACs}$. Reprinted with permission from Ref. [55]. Copyright 2016 American Chemical Society.

thermal conductivity. Lin and co-workers [48] investigated metal $(\mathrm{Cu}, \mathrm{Ag}, \mathrm{Au}, \mathrm{Pt}, \mathrm{Rh}, \mathrm{Pd}, \mathrm{Fe}$, Co and $\mathrm{Ir})$ doped hexagonal boron nitride nanosheets (h-BNNSs) with various defect sites, such as the boron vacancy and nitrogen edge, using a DFT method. Their calculations showed that the metal doped h-BNNSs should be stable under high temperatures. The catalytic activity of Co-doped h-BNNS was also systematically investigated by using $\mathrm{CO}$ oxidation as a probe, and the calculated low barrier suggested that the Co-BNNS was a viable catalyst for $\mathrm{CO}$ oxidation. Based on the electronic structure analysis, the catalytic capacity of Co-BNNS was attributed to the strong mixing between the cobalt $3 d$ orbitals and oxygen $2 p$ orbitals, which activated the adsorbed molecular or atomic oxygen. Therefore, these SACs are good candidates for low-cost, highly active and stable catalysts for the $\mathrm{CO}$ oxidation reaction.

Wang et al. [50] systematically investigated the catalytic activity for the oxygen reduction reaction of a two-dimensional Fe-phthalocyanine (Fe-Pc) monolayer catalyst with precisely-controlled distribution of Fe atoms, using comprehensive DFT calculations. The partial density of states for the $\mathrm{O}_{2}$ adsorbed Fe-Pc monolayer revealed that there was an obvious hybridization between the $\mathrm{O}_{2}-2 p$ orbitals and Fe- $3 d$ orbitals in both spin-up and spin-down channels. Especially, in the spin-down channel, the $\mathrm{O}_{2}-2 \pi$ state was partially occupied mostly owing to charge transfer from the Fe-Pc monolayer to the $\mathrm{O}_{2}$ molecule. These results revealed that $\mathrm{O}_{2}$ molecules can be sufficiently activated on the surface of a Fe-Pc monolayer, which would facilitate its subsequent reduction reactions. The subsequent oxygen reduction reaction steps preferred to proceed on the Fe-Pc monolayer through a more efficient $4 \mathrm{e}^{-}$ pathway $\left(\mathrm{O}_{2}\right.$ was reduced to two $\mathrm{H}_{2} \mathrm{O}$ molecules) than $2 \mathrm{e}^{-}$ pathway $\left(\mathrm{O}_{2}\right.$ is reduced to an $\mathrm{H}_{2} \mathrm{O}_{2}$ molecule). In addition, the Fe-Pc monolayer was more stable than the Fe-Pc molecule in an acidic medium, and could present good catalytic performance for the oxygen reduction reaction by the addition of axial ligands. Therefore, the Fe-Pc monolayer could be quite promising SACs with high efficiency for the oxygen reduction reaction in fuel cells.

Therefore, it can be concluded that: (1) 2D materials with lots of defect sites can be used as promising supports for the preparation of SACs; (2) the excellent catalytic property of the as-prepared SACs can be attributed to the electron transfer 
effects and synergistic effects between metal atoms and 2D supports.

\section{SACs anchored to the surface of metal NCs}

Although the activities and durability of colloidal catalysts are usually lower than those of supported catalysts $[19,24,29]$, they still exhibit several major advantages over those that are supported: (1) the intrinsic properties of metal colloidal catalysts can be relatively easily elucidated without the effect of the metal-support interaction; (2) the NCs with more uniform particle sizes can be obtained in the dispersed systems compared with those in the supported cases, especially under conditions of a high metal concentration, because the dispersed metal NCs can be easily concentrated by evaporating the solvent without changing the structures, in spite of the higher loading of metal on inorganic supports normally yields bigger particles with wider particle size dispersions; (3) high stability can be easily achieved for the colloidal catalysts owing to a good protection of the active sites by a protective agent. The present authors have successfully synthesized a series of colloidal NCs which possessed excellent catalytic activity for glucose oxidation [8,56-59], $\mathrm{NaBH}_{4} / \mathrm{KBH}_{4}$ hydrolysis [60-65] or $\mathrm{H}_{2} \mathrm{O}_{2}$ decomposition [66]. More recently, Pd/Au [19,67,68], IrPd/Au [69] and $\mathrm{Pt} / \mathrm{Au}$ [70] colloidal SACs have also been prepared by our group by using the galvanic replacement reaction or successive reduction method. All the as-prepared colloidal SACs catalysts exhibited excellent catalytic activity for aerobic glucose oxidation, the catalytic activity of these colloidal SACs was completely site-specific, and only the top atoms were effective for the catalysis.

The successive reduction method [71,72] is usually used to synthesize core@shell structured NCs [73,74]. Our research group has prepared colloidal $\mathrm{Au} / \mathrm{Pd}$ SACs using Pd as mother clusters, based on the strategy illustrated in Fig. 6 [75]. First, the dispersions of the PVP-protected Pd NCs were prepared by an alcohol reduction method. Then, aqueous solutions of $\mathrm{HAuCl}_{4}$ and PVP were rapidly added to the colloidal Pd dispersion containing L-ascorbic acid to prepare the Au/Pd SACs. Ultraviolet-visible absorption (UV-vis) spectroscopy, TEM, HAADF-STEM along with electron energy loss spectroscopy (EELS) were used to characterize the structure and catalytic activity for aerobic glucose oxidation. EELS results indicated that $\mathrm{Au}$ atoms were deposited in several areas only across the surface of the Pd55 mother clusters. DFT calculations indicated

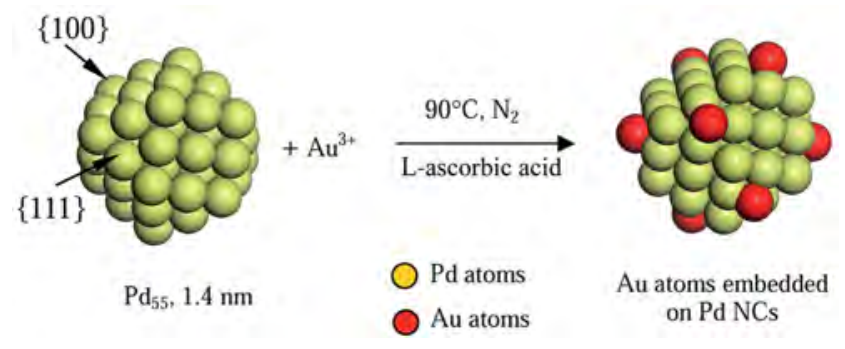

Fig. 6. Schematic illustration of the deposition of single Au atoms on the surface of Pd mother clusters. Reproduced with permission from Ref. [75]. Copyright 2014 The Royal Society of Chemistry. that the most preferable facets for the location of the first reduced $\mathrm{Au}$ atoms on the Pd surfaces should be the (111) plane, where each $\mathrm{Au}$ atom is coordinated by three surface Pd atoms. The catalytic activity of the colloidal $\mathrm{Au} / \mathrm{Pd}$ SACs were evaluated using glucose oxidation as a probe reaction, and the maximum catalytic activity of $\mathrm{Au}_{3} \mathrm{Pd}_{55}$ SACs was approximately 142040 mol-glucose $\mathrm{h}^{-1}$ mol-Au-1, which was approximately 17-40 times higher than those of the monometallic Au NC and the Pd NC catalysts, and 5-8 times higher than that of the $\mathrm{Au} / \mathrm{Pd}$ alloy NCs, although all of these NCs had almost the same particle size. Such a high catalytic activity should be related not only to the unique geometrical structure but also to the electronic properties of Au/Pd SACs. DFT calculations showed that $\mathrm{Au}$ atoms located at the surface of the $\mathrm{Pd}_{55}$ mother clusters were negatively charged, whereas the Pd atoms were positively charged, owing to the electronic charge transfer from the Pd atoms to the $\mathrm{Au}$ atoms. It was proposed that the negatively charged $\mathrm{Au}$ atoms acted as catalytic active sites for the glucose oxidation.

For the first time, the galvanic replacement reaction method was used for the preparation of colloidal PVP-protected Pd/Au SACs by our group $[19,67,68]$. Initially, Pd mother NCs with an average size of $1.8 \mathrm{~nm}$ were pre-fabricated by an alcohol reduction method, while the $\mathrm{Au}$ atoms were formed by the spontaneous replacement reaction between the $\mathrm{Au}^{3+}$ ions and $\mathrm{Pd}$ atoms decorating the top positions of the Pd NCs. UV-vis spectra showed that the absorbance intensity increased with an increasing $\mathrm{Au}$ content, indicating that $\mathrm{Au}$ atoms were deposited only in several areas across the surface of the Pd NCs. From HAADF-STEM images illustrated in Fig. 7(a), clear vacancies were observed in the corners of Pd NCs, which could be ascribed to the replacement reaction between the $\mathrm{Au}^{3+}$ and $\mathrm{Pd}$ atom since three Pd atoms would be consumed to form two $\mathrm{Au}$ atoms accompanied by a vacancy generation in the reaction. These vacancies provide reasonable evidence to confirm that the replacement reaction for the $\mathrm{Au}$ atom formation occurred at the top sites of the Pd mother clusters. The EELS map (Fig. 7(c)) showed that the Au was not very orderly in the NC and seemed to move in a certain area, suggesting that the top $\mathrm{Au}$ atoms were unstable and easily moved during the electron beam irradiation. On the basis of the HAADF-STEM and EELS results, the prepared $\mathrm{Au}$ atoms, or at least some of them, were shown to locate at the top position of the Pd NC.

The maximum catalytic activity of the top Au atoms was approximately $194980 \mathrm{~mol}_{\text {-glucose }} \mathrm{h}^{-1} \mathrm{~mol}_{\mathrm{Au}^{-1}}$. The specific activity was higher than that of the $\mathrm{Au}$ and $\mathrm{Pd}$ mother clusters by a factor of 20-30, and that of the Pd/Au alloy NCs by a factor of eight to ten, although all of these NCs had almost the same particle size. Such high catalytic activity should arise not only from the unique geometrical structure but also from the electronic properties of the top Au atoms. DFT calculations provided evidence that the Pd atoms donated electrons to the Au atoms and the top $\mathrm{Au}$ atoms in the $\mathrm{Au} / \mathrm{Pd}$ SACs were indeed negatively charged. Additionally, electron transfer from the anionic $\mathrm{Au}$ atoms to $\mathrm{O}_{2}$ generated a superoxo-like species, which plays a crucial role in the oxidation of the glucose.

$\mathrm{Au} / \mathrm{Pd}$ SACs were also prepared for enhanced $\mathrm{H}_{2} \mathrm{O}_{2}$ produc- 

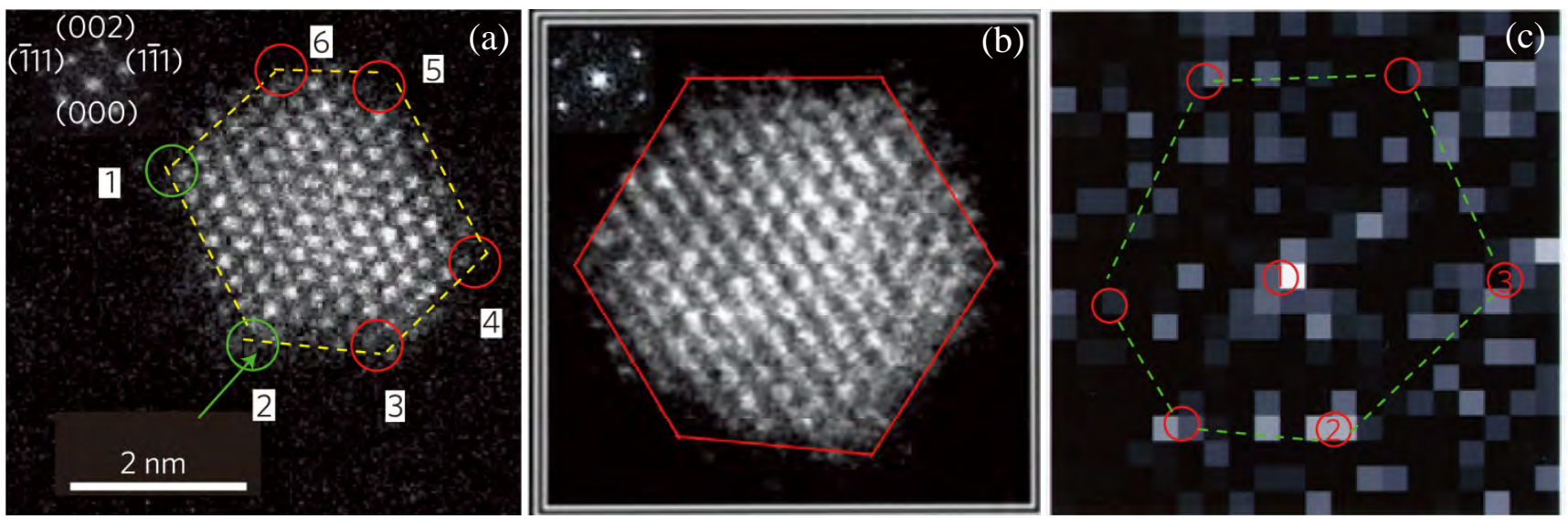

Fig. 7. (a) HAADF-STEM image of single Au/Pd SACs. (b) HAADF-STEM image and (c) EELS mapping of Au/Pd SACs recorded along the [110] zone axis. The dotted green hexagon marks the shape of the cluster estimated on the basis of EELS results and red circles indicate the presence of the top Au atoms. Reprinted with permission from Ref. [19]. Copyright 2012 Nature Publishing Group.

tion [76], and the results showed that discrete guest Pd atoms dispersed on a $\mathrm{Au}(111)$ host surface would significantly improve the reactivity of the surface toward oxygen reduction. The dependence of the Pd content in $\mathrm{Au} / \mathrm{Pd} \mathrm{NCs}$ was investigated experimentally by a sequential reduction synthetic method with respect to the oxygen reduction reaction. A pronounced increase in oxygen reduction selectivity toward $\mathrm{H}_{2} \mathrm{O}_{2}$ production, approaching 95\%, was observed for Pd molar contents of $8 \%$. Further increase of the Pd concentration in the nanoalloys led to losses in $\mathrm{H}_{2} \mathrm{O}_{2}$ selectivity, which dropped below $10 \%$ for Pd concentrations of $50 \%$. The enhancement of $\mathrm{H}_{2} \mathrm{O}_{2}$ production was attributed to the presence of Pd monomers surrounded by gold at the surface of $\mathrm{Au} / \mathrm{Pd}$ nanoalloys whereas the decrease at $\mathrm{Pd}$ concentrations above $15 \%$ arose from the presence of contiguous Pd atoms. It was expected that by a rational design of alloying components and composition, product distribution could be directed to avoid $0-0$ bond breaking during the reduction process, which is a problem that has received attention for a long time for the industrial direct synthesis of $\mathrm{H}_{2} \mathrm{O}_{2}$ from $\mathrm{O}_{2}$ and $\mathrm{H}_{2}$. DFT results suggested that two adjacent $\mathrm{Pd}$ atoms should support $\mathrm{H}_{2} \mathrm{O}$ formation instead of $\mathrm{H}_{2} \mathrm{O}_{2}$, while single $\mathrm{Pd}$ atoms could be directed to avoid $\mathrm{O}-\mathrm{O}$ bond breaking.

PVP-protected colloidal Pt/Au SACs with Au atoms located at active top sites were synthesized by a replacement reaction using 1.4-nm Pt NCs as mother clusters, with the consideration that the replacement reaction between $\mathrm{Pt}$ and $\mathrm{Au}^{3+}$ ions is difficult. The results of HAADF-STEM and the EELS map indicated that at least some of the $\mathrm{Au}$ atoms were located at the top site of the cluster. The catalytic activity for the aerobic glucose oxidation of the prepared Pt/Au SACs was as high as 134700

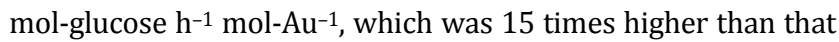
of the monometallic Au NCs, and more than 4 times higher than the Pt/Au alloy bimetallic NCs with nearly the same particle size. The high activity of the prepared Pt/Au SACs could also be attributed to the existence of the negatively charged top $\mathrm{Au}$ atoms.

It is well accepted that trimetallic NCs usually have the advantages of high selectivity and activity over the corresponding mono- and bi-metallic counterparts [9,77-79]. Thus, colloidal PVP protected (IrPd)/Au SACs using Ir/Pd NCs as the mother cluster were synthesized and tested. The results indicated that the addition of Ir could enhance the catalytic activity for the aerobic glucose oxidation of the Pd/Au bimetallic counterpart [69]. HAADF-STEM was employed to study the exact composition and structure of the (IrPd)/Au SACs. Clear vacancies arising from the replacement reaction were also observed in the corner positions, which reasonably verified the occurrence of the replacement reaction for the formation of $\mathrm{Au}$ atoms at the top sites of Ir/Pd NCs. By comparing the catalytic activities for glucose oxidation of a series of (IrPd)/Au trimetallic NCs with different compositions, $\operatorname{Ir}_{132} \mathrm{Pd}_{15} \mathrm{Au}_{12}$ SACs exhibited a catalytic activity of approximately 343190 mol-glucose $\mathrm{h}^{-1} \mathrm{~mol}_{-} \mathrm{Au}^{-1}$, which is the most effective catalysts for glucose oxidation reported to date (Fig. 8).

The highest catalytic activity of the prepared $\operatorname{Ir}_{132} \mathrm{Pd}_{15} \mathrm{Au}_{12}$ SACs towards aerobic glucose oxidation could be attributed to the geometric effect and the electronic effect. It was believed that the electronic structure of the top $\mathrm{Au}$ atoms might be

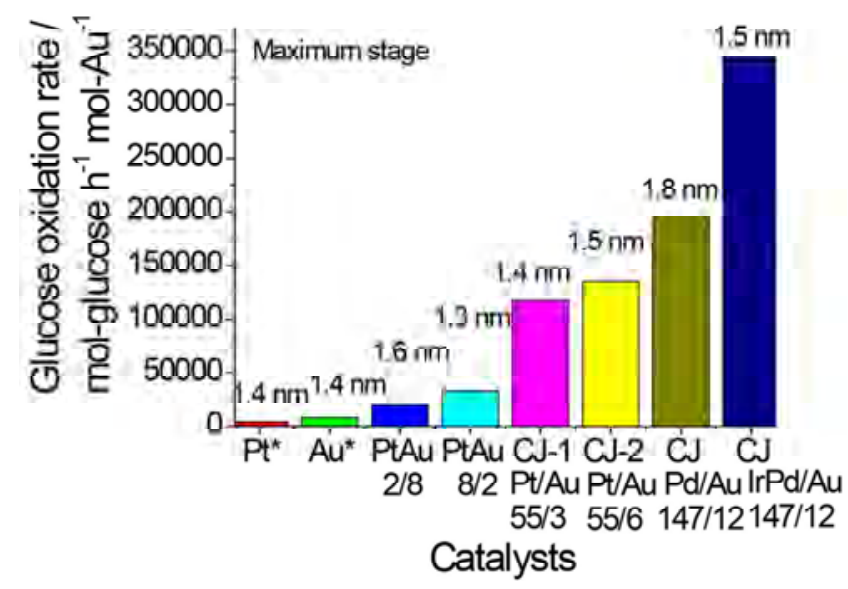

Fig. 8. Comparison of the catalytic activity of $\mathrm{Pt} / \mathrm{Au}, \mathrm{Pd} / \mathrm{Au}, \mathrm{IrPd} / \mathrm{Au}$ SACs, Au, Pt, and Pt/Au alloy NCs for aerobic glucose oxidation. Reprinted with permission from Ref. [70]. Copyright 2016 Nature Publishing Group. 


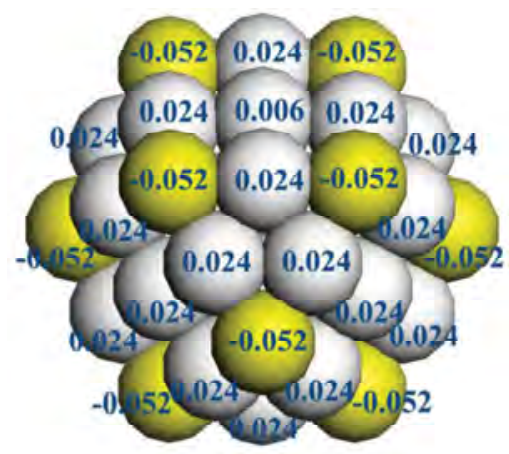

(a)

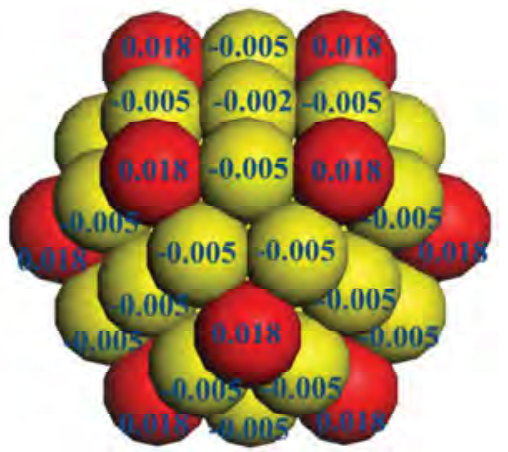

(b)

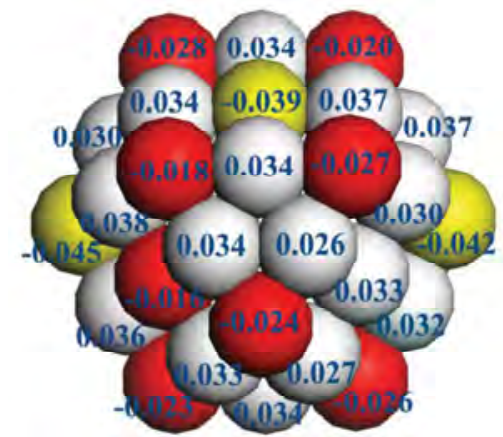

(c)

Fig. 9. DFT calculations on electronic structures of (a) CJ-Pd ${ }_{43} \mathrm{Ir}_{12}$, (b) CJ-Pd $\mathrm{Pd}_{43} \mathrm{Au}_{12}$, (c) CJ-( $\left.\mathrm{Ir}_{17} \mathrm{Pd}_{26}\right) \mathrm{Au}_{12} \mathrm{NCs}$. Red: Au atoms; White: $\mathrm{Pd}$ atoms; Yellow: Ir atoms. Reproduced with permission from Ref. [69]. Copyright 2015 WILEY-VCH Verlag GmbH \& Co. KGaA, Weinheim.

changed through at least two electronic charge transfer modes for the trimetallic NCs, which are a single charge transfer from the Pd atom to $\mathrm{Au}$ atom, and from the Pd atom to Ir atom. The DFT calculation results shown in Fig. 9 confirmed the presence of the two kinds of charge transfers, and the presence of negatively charged $\mathrm{Au}$ and Ir atoms. The synergistic effects arising from the two types of charge transfer modes might play crucial roles in achieving the highest catalytic activity of the (IrPd)/Au SACs. It was accepted that electron transfer from the anionic $\mathrm{Au}$ and Ir atoms to $\mathrm{O}_{2}$ also generated a hydroperoxo-like species, and then enhanced the catalytic activity of the SACs for aerobic glucose oxidation. DFT calculations were used to study the interaction of the adsorbed $\mathrm{O}_{2}$ and (IrPd)/Au NCs, and the results (Fig. 10) showed that the adsorbed $\mathrm{O}_{2}$ molecule on the (111) face of $\mathrm{Au}_{13}$ and $\mathrm{Ir}_{2} \mathrm{Pd}_{2} \mathrm{Au}$ 9 model clusters were indeed negatively charged. It was also revealed that the bond lengths of the $\mathrm{O}_{2}$ molecules adsorbed on the (111) faces of $\mathrm{Au}_{13}$ and $\operatorname{Ir}_{2} \mathrm{Pd}_{2} \mathrm{Au}_{9}$ model clusters were larger than the original bond length $(1.225$ $\AA$ ) of a free-standing $\mathrm{O}_{2}$ molecule, which suggested that the $0-0$ bond was weakened and the relatively stable $\mathrm{O}_{2}$ molecule activated when it was absorbed onto the surface of these NCs. In addition, the DFT calculation results showed that the incorporation of the second and third elements into Au NCs could increase the charge density of the adsorbed $\mathrm{O}_{2}$ molecules, and that the $\mathrm{O}_{2}$ molecules adsorbed on the (111) face formed by the $\mathrm{Ir}, \mathrm{Pd}$ and $\mathrm{Au}$ atoms showed the highest negatively charged value. This should be the main reasons for the high catalytic activity of the prepared (IrPd)/Au SACs.

Colloidal Ag/Au SACs were prepared to study the effects of atomic substitution on the electronic structure, stability, and photophysical properties of Ag clusters. Osman et al. [80] successfully synthesized a pure Au-doped $\mathrm{Ag}_{25}(\mathrm{SR})_{18}$ cluster, $\mathrm{Ag}_{24} \mathrm{Au}(\mathrm{SR})_{18}$ (2,4-dimethylbenzenethiol), using a galvanic exchange procedure. Optical spectroscopy, mass spectrometry, and single-crystal XRD analyses unambiguously confirmed the central Ag substitution of $\left[\mathrm{Ag}_{25}(\mathrm{SR})_{18}\right]^{-}$with a $\mathrm{Au}$ atom, forming a single nanoparticle composition of $\left[\mathrm{Ag}_{24} \mathrm{Au}\left(\mathrm{SPhMe}_{2}\right)_{18}\right]^{-}$that preserved the structural framework of $\mathrm{Ag}_{25}$. Heteroatom doping of $\mathrm{Ag}_{25}$ caused an increase in the stability of the material and changes in the electronic, optical, and luminescence properties. It is worth mentioning that $\left[\mathrm{Ag}_{24} \mathrm{Au}\left(\mathrm{SPhMe}_{2}\right)_{18}\right]^{-}$exhib- ited a 25-fold photoluminescence enhancement compared with $\left[\mathrm{Ag}_{25}\left(\mathrm{SPhMe}_{2}\right)_{18}\right]^{-}$. Recently, Pd/Cu SACs were also investigated for the hydrogenation of styrene and acetylene as compared with pure $\mathrm{Cu}$ or Pd metal alone [24]. The results showed that isolated $\mathrm{Pd}$ atoms in a $\mathrm{Cu}$ (111) surface substantially lowered the energy barrier to both hydrogen uptake on and subsequent desorption from the Cu metal surface.

In summary, high catalytic activity of colloidal SACs is determined by their geometric structure and electronic structure. Morphological and electronic control of SACs is very important for the development of the next generation of highly efficient catalysts.

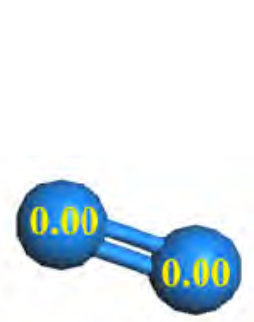

(a)

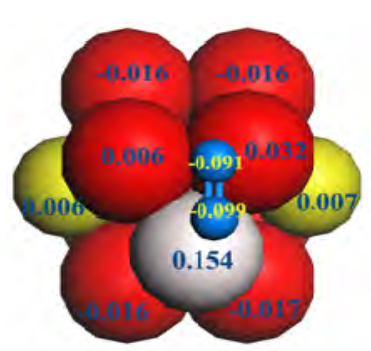

(c)

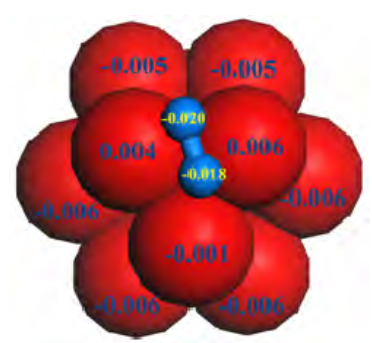

(b)

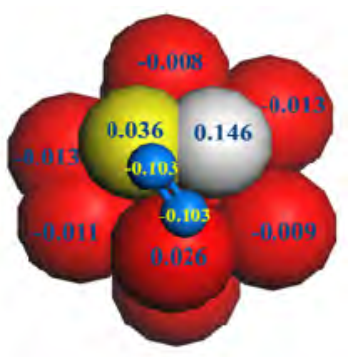

(d)
Fig. 10. Electronic charge, bond length, and bond order of an oxygen molecule adsorbed on the (111) face of $\mathrm{Au}_{13}$ and $\mathrm{Ir}_{2} \mathrm{Pd}_{2} \mathrm{Au} 9$ model NC calculated by DFT. Red: Au atoms; White: Pd atoms; Yellow: Ir atoms. (a Free-standing $\mathrm{O}_{2}$ molecule. (b) $\mathrm{O}_{2}$ adsorbed on the (111) face formed by three $\mathrm{Au}$ atoms of $\mathrm{Au}_{13}$. (c) $\mathrm{O}_{2}$ molecule adsorbed on the (111) face formed by $2 \mathrm{Au}$ and $1 \mathrm{Pd}$ atom of the $\mathrm{Ir}_{2} \mathrm{Pd}_{2} \mathrm{Au}_{9}$ model NC. (d) $\mathrm{O}_{2}$ molecule adsorbed on the (111) face formed by with $1 \mathrm{Au}, 1 \mathrm{Pd}$ and $1 \mathrm{Ir}$ atom of $\operatorname{Ir}_{2} \mathrm{Pd}_{2} \mathrm{Au}_{9}$ model NC. Reproduced with permission from Ref. [69]. Copyright 2015 WILEY-VCH Verlag GmbH \& Co. KGaA, Weinheim. 


\section{Conclusions}

In this review, we highlight the recent advances in the preparation, characterization, and catalytic performance evaluations of SACs, with a focus on single atoms anchored to metal oxides, two-dimensional materials and the surface of metal NCs. Unambiguously, both supported SACs and colloidal SACs exhibit higher catalytic activity and selectivity than their supported nano-counterparts with satisfying stability in various reactions. Although supported SACs exhibit an improved catalytic performance, it remains a challenge to produce them on a large scale owing to their low production efficiency. The preparation of colloidal SACs is rather mature but suffers from low recyclability and poor durability. For future studies, efforts to enhance atomically dispersive efficiency of supported SACs or load colloidal SACs on supports to improve their stabilities should be considered.

SACs integrate the excellent metal use of homogeneous catalysts with the robustness and facile recovery offered by heterogeneous catalysts [81], and their outstanding catalytic performance is attributable to their unique structure which consists of individual active metal atoms. Moreover, the interaction between active metal atoms and supports has an impact on the catalytic properties of SACs. Although many theoretical studies based on the experimental results have been performed to understand the catalytic properties of SACs, little work has been done on the prediction of new SACs based on the theoretical results. For future studies, more computational chemistry should be performed to guide experiments towards promising SACs. Furthermore, the studies of SACs performed so far have mainly focused on noble metals and single-active sites, with less attention paid to non-noble metals SACs or atomically dispersive multi-metals on supports with multi-active sites.

The final objective is to design SACs with $100 \%$ atomic dispersity to offer the maximum atom efficiency. A deep molecular-level understanding of the synthesis-property-function relations in SACs is still a challenge, especially identification of (1) the precise geometric location of the isolated individual metal atoms with respect to the support surface structure, and (2) the electronic properties of the isolated metal atoms and their interactions with the supports. We believe that SACs with high catalytic performance and low cost could be fabricated in the future, which will have the potential to contribute tremendously to the efficient catalytic reactions in various significant areas.

\section{References}

[1] P. Wang, H. Z. Liu, J. R. Niu, R. Li, J. Ma, Catal. Sci. Technol., 2014, 4, 1333-1339.

[2] Z. Balogh, G. Halasi, B. Korbély, K. Hernadi, Appl. Catal. A, 2008, 344, 191-197.

[3] M. Lewandowski, G. S. Babu, M. Vezzoli, M. D. Jones, R. E. Owen, D. Mattia, P. Plucinski, E. Mikolajska, A. Ochenduszko, D. C. Apperley, Catal. Commun., 2014, 49, 25-28.

[4] H. J. You, S. C. Yang, B. J. Ding, H. Yang, Chem. Soc. Rev., 2013, 42, 2880-2904.

[5] G. Halasi, I. Ugrai, F. Solymosi, J. Catal., 2011, 281, 309-317.

[6] M. H. Liu, W. Y. Yu, H. F. Liu. J. Mol. Catal. A, 1999, 138, 295-303.

[7] H. J. Zhang, W. Q. Li, Y. J. Gu, S. W. Zhang, J. Nanosci. Nanotechnol., 2014, 14, 5743-5751.

[8] H. J. Zhang, N. Toshima, J. Colloid Interface Sci., 2013, 394, $166-176$

[9] H. J. Zhang, M. Okumura, N. Toshima, J. Phys. Chem. C, 2011, 115, 14883-14891.

[10] S. Vajda, M. J. Pellin, J. P. Greeley, C. L. Marshall, L. A. Curtiss, G. A. Ballentine, J. W. Elam, S. Catillon-Mucherie, P. C. Redfern, F. Mehmood, P. Zapol, Nat. Mater., 2009, 8, 213-216.

[11] J. Lin, B. T. Qiao, N. Li, L. Li, X. C. Sun, J. Y. Liu, X. D. Wang, T. Zhang, Chem. Commun., 2015, 51, 7911-7914.

[12] M. Turner, V. B. Golovko, O. P. Vaughan, P. Abdulkin, A. Berenguer-Murcia, M. S. Tikhov, B. F. Johnson, R. M. Lambert, Nature, 2008, 454, 981-983.

[13] X. F. Yang, A. Q. Wang, B. T. Qiao, J. Li, J. Y. Liu, T. Zhang, Acc. Chem. Res., 2013, 46, 1740-1748.

[14] P. P. Hao, Y. Y. Jin, J. Ren, Z. Li, Prog. Chem., 2015, 27, 1689-1704.

[15] B. Long, Y. Tang, J. Li, Nano Res., 2016, 9, 3868-3880.

[16] P. Wu, P. Du, H. Zhang, C. X. Cai, Phys. Chem. Chem. Phys., 2015, 17, 1441-1449.

\section{Graphical Abstract}

Chin. J. Catal., 2017, 38: 1528-1539 doi: 10.1016/S1872-2067(17)62770-0

\section{Preparation, characterization and catalytic performance of single-atom catalysts}

Liqiong Wang, Liang Huang*, Feng Liang, Simin Liu, Yuhua Wang, Haijun Zhang*

Wuhan University of Science and Technology

Single-atom catalysts (SACs) have become a desirable research topic. The preparation, characterization and catalytic performance of three kinds of SACs with single atoms anchored onto metal oxides, two-dimensional materials and metal nanoclusters are summarized.

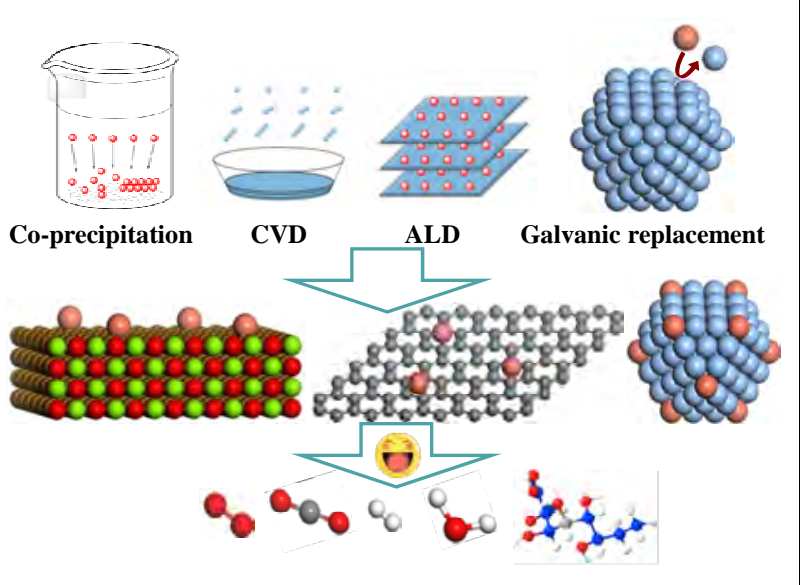


[17] B. L. He, J. S. Shen, Z. X. Tian, Phys. Chem. Chem. Phys., 2016, 18, 24261-24269.

[18] J. X. Liang, X. Yang, A. Q. Wang, T. Zhang, J. Li, Catal. Sci. Technol., 2016, 6, 6886-6892.

[19] H. J. Zhang, T. Watanabe, M. Okumura, M. Haruta, N. Toshima, Nat. Mater., 2012, 11, 49-52.

[20] B. T. Qiao, A. Q. Wang, X. F. Yang, L. F. Allard, Z. Jiang, Y. T. Cui, J. Y. Liu, J. Li, T. Zhang, Nat. Chem., 2011, 3, 634-641.

[21] X. R. Cao, Y. F. Ji, Y. Luo, J. Phys. Chem. C, 2015, 119, 1016-1023.

[22] G. Vile, D. Albani, M. Nachtegaal, Z. P. Chen, D. Dontsova, M. Antonietti, N. Lopez, J. Perez-Ramirez, Angew. Chem. Int. Ed., 2015, 54, 11265-11269.

[23] G. X. Pei, X. Y. Liu, A. Q. Wang, A. F. Lee, M. A. Isaacs, L. Li, X. L. Pan, X. F. Yang, X. D. Wang, Z. J. Tai, K. Wilson, T. Zhang, ACS Catal., 2015, 5, 3717-3725.

[24] G. Kyriakou, M. B. Boucher, A. D. Jewell, E. A. Lewis, T. J. Lawton, A. E. Baber, H. L. Tierney, M. Flytzani-Stephanopoulos, E. C. Sykes, Science, 2012, 335, 1209-1212.

[25] J. Lin, A. Q. Wang, B. T. Qiao, X. Y. Liu, X. F. Yang, X. D. Wang, J. X. Liang, J. Li, J. Y. Liu, T. Zhang, J. Am. Chem. Soc., 2013, 135, 15314-15317.

[26] K. Ding, A. Gulec, A. M. Johnson, N. M. Schweitzer, G. D. Stucky, L. D. Marks, P. C. Stair, Science, 2015, 350, 189-192.

[27] X. G. Li, W. T. Bi, L. Zhang, S. Tao, W. S. Chu, Q. Zhang, Y. Luo, C. Z. Wu, Y. Xie, Adv. Mater., 2016, 28, 2427-2431.

[28] H. T. Wang, Q. X. Wang, Y. C. Cheng, K. Li, Y. B. Yao, Q. Zhang, C. Z. Dong, P. Wang, U. Schwingenschlogl, W. Yang, X. X. Zhang, Nano Lett., 2012, 12 141-144.

[29] W. L. Wang, E. J. G. Santos, B. Jiang, E. D. Cubuk, C. Ophus, A. Centeno, A. Pesquera, A. Zurutuza, J. Ciston, R. Westervelt, E. Kaxiras, Nano Lett., 2014, 14, 450-455.

[30] S. Yang, Y. J. Tak, J. Kim, A. Soon, H. Lee, ACS Catal., 2017, 7, 1301-1307.

[31] S. Yang, J. Kim, Y. J. Tak, A. Soon, H. Lee, Angew. Chem. Int. Ed., 2016, 55, 2058-2062.

[32] J. Xing, J. F. Chen, Y. H. Li, W. T. Yuan, Y. Zhou, L. R. Zheng, H. F. Wang, P. Hu, Y. Wang, H. J. Zhao, Y. Wang, H. G. Yang, Chemistry, 2014, 20, 2138-2144.

[33] B. T. Qiao, J. Lin, A. Q. Wang, Y. Chen, T. Zhang, J. Y. Liu, Chinese J. Catal., 2015, 36, 1505-1511.

[34] B. T. Qiao, J. X. Liang, A. Q. Wang, C. Q. Xu, J. Li, T. Zhang, J. Y. Liu, Nano Res., 2015, 8, 2913-2924.

[35] Y. Sato, Y. Soma, T. Miyao, S. Naito, Appl. Catal. A, 2006, 304, 78-85.

[36] L. L. Zhang, A. Q. Wang, J. T. Miller, X. Y. Liu, X. F. Yang, W. T. Wang, L. Li, Y. Q. Huang, C. Y. Mou, T. Zhang, ACS Catal., 2014, 4, 1546-1553.

[37] M. Moses-DeBusk, M. Yoon, L. F. Allard, D. R. Mullins, Z. L. Wu, X. F. Yang, G. Veith, G. M. Stocks, C. K. Narula, J. Am. Chem. Soc., 2013, 135, 12634-12645.

[38] X. K. Gu, B. T. Qiao, C. Q. Huang, W. C. Ding, K. J. Sun, E. S. Zhan, T. Zhang, J. Y. Liu, W. X. Li, ACS Catal., 2014, 4, 3886-3890.

[39] P. P. Hu, Z. W. Huang, Z. Amghouz, M. Makkee, F. Xu, F. Kapteijn, A. Dikhtiarenko, Y. X. Chen, X. Gu, X. F. Tang, Angew. Chem. Int. Ed., 2014, 53, 3418-3421.

[40] P. X. Liu, Y. Zhao, R. X. Qin, S. G. Mo, G. X. Chen, L. Gu, D. M. Chevrier, P. Zhang, Q. Guo, D. D. Zang, B. H. Wu, G. Fu, N. F. Zheng, Science, 2016, 352, 797-800.

[41] D. H. Deng, K. S. Novoselov, Q. Fu, N. F. Zheng, Z. Q. Tian, X. H. Bao, Nat. Nanotechnol., 2016, 11, 218-230.

[42] S. Z. Butler, S. M. Hollen, L. Y. Cao, Y. Cui, J. A. Gupta, H. R. Gutierrez, T. F. Heinz, S. S. Hong, J. X. Huang, A. F. Ismach, E. John-
ston-Halperin, M. Kuno, V. V. Plashnitsa, R. D. Robinson, R. S. Ruoff, S. Salahuddin, J. Shan, L. Shi, M. G. Spencer, M. Terrones, W. Windl, J. E. Goldberger, ACS Nano, 2013, 7, 2898-2926.

[43] H. J. Qiu, Y. Ito, W. Cong, Y. Tan, P. Liu, A. Hirata, T. Fujita, Z. Tang, M. Chen, Angew. Chem. Int. Ed., 2015, 54, 14031-14035.

[44] S. H. Sun, G. X. Zhang, N. Gauquelin, N. Chen, J. G. Zhou, S. L. Yang, W. F. Chen, X. B. Meng, D. S. Geng, M. N. Banis, R. Y. Li, S. Y. Ye, S. Knights, G. A. Botton, T. K. Sham, X. L. Sun, Sci. Rep., 2013, 3, 1755-1763.

[45] H. Yan, H. Cheng, H. Yi, Y. Lin, T. Yao, C. L. Wang, J. J. Li, S. Q. Wei, J. L. Lu, J. Am. Chem. Soc., 2015, 137, 10484-10487.

[46] G. P. Gao, Y. Jiao, E. R. Waclawik, A. J. Du, J. Am. Chem. Soc., 2016, 138, 6292-6297.

[47] P. Zhao, Y. Su, Y. Zhang, S. J. Li, G. Chen, Chem. Phys. Lett., 2011, 515, 159-162.

[48] S. Lin, X. X. Ye, R. S. Johnson, H. Guo, J. Phys. Chem. C, 2013, 117, 17319-17326.

[49] X. Zhang, J. C. Lei, D. H. Wu, X. D. Zhao, Y. Jing, Z. Zhou, J. Mater. Chem. A, 2016, 4, 4871-4876.

[50] Y. Wang, H. Yuan, Y. F. Li, Z. F. Chen, Nanoscale, 2015, 7, 11633-11641.

[51] Y. F. Li, Z. Zhou, G. T. Yu, W. Chen, Z. F. Chen, J. Phys. Chem. C, 2010, 114, 6250-6254.

[52] J. Halim, S. Kota, M. R. Lukatskaya, M. Naguib, M. Q. Zhao, E. J. Moon, J. Pitock, J. Nanda, S. J. May, Y. Gogotsi, M. W. Barsoum, Adv. Funct. Mater., 2016, 26, 3118-3127.

[53] Q. K. Hu, D. D. Sun, Q. H. Wu, H. Y. Wang, L. B. Wang, B. Z. Liu, A. G. Zhou, J. L. He, J. Phys. Chem. A, 2013, 117, 14253-14260.

[54] Y. Wang, X. C. Wang, M. Antonietti, Angew. Chem. Int. Ed., 2012, 51, 68-89.

[55] G. Gao, Y. Jiao, E. R. Waclawik, A. Du, J. Am. Chem. Soc., 2016, 138, 6292-6297.

[56] H. J. Zhang, Y. N. Cao, L. L. Lu, Z. Cheng, S. W. Zhang, Metall. Mater. Trans. B, 2014, 46, 523-530.

[57] H. J. Zhang, N. Toshima, Catal. Sci. Technol., 2013, 3, 268-278.

[58] H. J. Zhang, N. Toshima, K. Takasaki, M. Okumura, J. Alloys Comp., 2014, 586, 462-468.

[59] H. J. Zhang, J. Okuni, N. Toshima, J. Colloid Interface Sci., 2011, 354, 131-138.

[60] C. P. Jiao, Z. L. Huang, X. F. Wang, H. J. Zhang, L. L. Lu, S. W. Zhang, RSC Adv., 2015, 5, 34364-34371.

[61] D. C. Kong, Y. J. Gu, S. Xiang, P. Wang, J. Cheng, H. J. Zhang, S. W. Zhang, Chem. J. Chin. Univ., 2013, 34, 2377-2382.

[62] X. F. Wang, S. R. Sun, Z. L. Huang, H. J. Zhang, S. W. Zhang, Int. J. Hydrogen Energy, 2014, 39, 905-916.

[63] X. Y. Zhou, W. Q. Li, W. Li, L. Su, W. G. Zha, Z. N. Zhou, H. J. Zhang, L. L. Lu, S. W. Zhang, F. L. Li, Chem. Online, 2015, 78, 237-241.

[64] W. G. Zhao, L. Su, Z. N. Zhou, H. J. Zhang, L. L. Lu, S. W. Zhang, Acta Phys.-Chim. Sin., 2015, 31, 145-152.

[65] X. F. Wang, Y. N. Cao, S. R. Sun, Z. L. Huang, H. J. Zhang, S. W. Zhang, Rare Metal Mater. Eng., 2015, 44, 753-758.

[66] H. J. Zhang, X. G. Deng, C. P. Jiao, L. L. Lu, S. W. Zhang, Mater. Res. Bull., 2016, 79, 29-35.

[67] H. J. Zhang, N. Toshima, J. Nanosci. Nanotechnol., 2013, 13, 5405-5412.

[68] H. J. Zhang, T. Watanabe, M. Okumura, M. Haruta, N. Toshima, J. Catal., 2013, 305, 7-18. 
[69] H. J. Zhang, L. L. Lu, K. Kawashima, M. Okumura, M. Haruta, N. Toshima, Adv. Mater., 2015, 27, 1383-1388.

[70] H. J. Zhang, L. Q. Wang, L. L. Lu, N. Toshima, Sci. Rep., 2016, 6, 30752-30762.

[71] T. Nakamura, Y. Tsukahara, T. Yamauchi, H. Mori, Y. Wada, Chem. Lett., 2007, 36, 154-155.

[72] C. P. Jiao, Z. L. Huang, H. J. Zhang, S. W. Zhang, Prog. Chem., 2015, $27,472-481$.

[73] Z. Ban, Y. A. Barnakov, F. Li, V. O. Golub, C. J. O'Connor, J. Mater. Chem., 2005, 15, 4660-4662.

[74] J. Yang, J. Y. Lee, H. P. Too, J. Phys. Chem. B, 2005, 109, 19208-19212.
[75] H. J. Zhang, K. Kawashima, M. Okumura, N. Toshima, J. Mater. Chem. A, 2014, 2, 13498-13508.

[76] J. S. Jirkovsky, I. Panas, E. Ahlberg, M. Halasa, S. Romani, D. J. Schiffrin, J. Am. Chem. Soc., 2011, 133, 19432-19441.

[77] H. J. Zhang, N. Toshima, Appl. Catal. A, 2011, 400, 9-13.

[78] H. J. Zhang, L. L. Lu, Y. N. Cao, S. Du, Z. Cheng, S. W. Zhang, Mater. Res. Bull., 2014, 49, 393-398.

[79] W. Q. Li, W. G. Zhao, X. Y. Zhou, L. Su, H. J. Zhang, L. L. Lu, S. W. Zhang, Chem. J. Chin. Univ., 2014, 35, 2164-2169.

[80] M. S. Bootharaju, C. P. Joshi, M. R. Parida, O. F. Mohammed, O. M. Bakr, Angew. Chem. Int. Ed., 2016, 55, 922-926.

[81] S. X. Liang, C. Hao, Y. T. Shi, ChemCatChem, 2015, 7, 2559-2567.

\title{
单原子催化剂的制备、表征及催化性能
}

\author{
王丽琼 ${ }^{\mathrm{a}}$, 黄 亮, 费, 梁 峰 ${ }^{\mathrm{b}}$, 刘思敏 ${ }^{\mathrm{b}}$, 王玉华 ${ }^{\mathrm{c}}$, 张海军 ${ }^{\mathrm{a}}$ * \\ a武汉科技大学耐火材料与冶金国家重点实验室, 湖北武汉 430081 \\ 武汉科技大学化学与化工学院, 湖北武汉 430081 \\ c 武汉科技大学冶金工业过程系统科学湖北省重点实验室, 湖北武汉 430081
}

\begin{abstract}
摘要: 单原子催化剂(SACs)是指金属以单原子形式均匀分散在载体上形成的具有优异催化性能的催化剂. 与传统载体型 催化剂相比, SACs 具有活性高、选择性好及贵金属利用率高等优点, 在氧化反应、加氢反应、水煤气变换、光催化制氢以 及电化学催化等领域都具有广泛应用, 是目前催化领域的研究热点之一. 常见的SACs制备方法有共沉淀法、浸渍法、置 换反应法、原子层沉积法以及反奥斯瓦尔德熟化法等. 实验及理论研究表明, 单原子催化剂高的活性和选择性可归因于活 性金属原子和载体之间的相互作用及由此引起的电子结构改变. 载体是影响单原子催化剂性能的重要因素之一. 目前常 用的SACs载体有金属氧化物、二维材料和金属纳米团簇等, 本文着重综述了这三种负载型SACs的制备、表征、催化性能 及催化机理, 并概述了SACs未来可能的发展方向和应用.

研究表明, 共沉淀法、湿浸渍法和反奥斯瓦尔德熟化法等方法可用来制备氧化物负载的SACs. 高角环形暗场像-扫描 透射电子显微镜(HAADF-STEM)表明金属是以单原子形式均匀分散在载体上, 近边X射线吸收精细结构(XANES)结果表 明金属原子与载体之间存在着强相互作用. 实验和理论研究均表明该类催化剂在 $\mathrm{CO}$ 氧化反应、水煤气转化及乙炔加氢生 成乙烯等反应中具有高的催化活性和稳定性. 采用化学气相沉积法和原子层沉积法等方法可以将金属原子稳定地负载在 具有缺陷活性位点的石墨烯、MXene及六方氮化硼等二维材料上并相应制备出SACs. X射线吸收精细结构谱(EXAFS)和 XANES分析表明样品中金属以单原子形式存在, 而且金属原子与载体之间也存在着强相互作用, 理论计算表明金属原子 与二维载体之间的电荷转移是SACs活性高的主要原因. 置换反应法和连续还原法是制备溶胶型SACs的有效方法, 其中置 换反应法可将活性金属原子原位组装在金属模板团簇的顶点位置, 连续还原法可将活性原子负载于金属模板团簇的表面. DFT计算表明活性原子和金属模板团簇之间存在电荷转移效应, 这是溶胶型SACs具有非常高的催化活性的主要原因.
\end{abstract}

SACs下一步的研究方向可能是: (1) 研究开发新型SACs, 尽可能提高催化剂中活性金属原子的含量; (2) 深入研究 SACs的结构、活性以及催化机理之间的关系; (3) 尝试将SACs大规模应用于工业催化.

关键词: 单原子催化剂; 制备方法; 催化活性; 表征; 电子结构

收稿日期: 2016-10-29. 接受日期: 2016-12-19. 出版日期: 2017-09-05.

*通讯联系人. 电话/传真: (027)68862829; 电子信箱: zhanghaijun@wust.edu.cn

\#通讯联系人. 电话: (027)68862258; 电子信箱: huangliang1986@wust.edu.cn

基金来源：国家自然科学基金(51472184, 51472185); 湖北省科技支撑计划对外科技合作项目(2013BHE003); 湖北省教育厅高等 学校优秀中青年科技创新团队计划(T201602).

本文的英文电子版由Elsevier出版社在ScienceDirect上出版(http://www.sciencedirect.com/science/journal/18722067). 